\title{
Co-Creation of Value in Banking Relationships
}

\author{
Luay Khreish \\ Credit Select, Australia
}

\begin{abstract}
The purpose of this study was to understand value creation on a dyadic level within banking relationships (that is between a business-banking relationship manager and a business-banking customer). It also aimed to provide business-banking specific definitions for the Co-Creation of Value (CCoV) within the said context. A quantitative survey questionnaire was developed and distributed to two respondent groups (business-banking relationship managers and business-banking customers) from a major Australian Bank. $\mathrm{CCoV}$ was found to be positively correlated with relationship longevity both from the relationship manager's and customer's perspectives. A limitation of this study is that due to the lack of extant literature on CCoV, only one measure for this construct was developed and utilised. This research will assist banks when formulating relationship strategy, in that, it provides an insight into customer perceived value. It also provides insight into banker perceived value. Therefore, customers will be able to reciprocate value thus enabling the development of deeper customer/bank relationships. There is little existing research that covers CCoV, particularly in a banking context, so this study provides a definition of CCoV within the said context. This will be important to theorists and bankers alike when theorists attempt to extend the knowledge of CCoV in banking context and when bankers are formulating relationship strategy.
\end{abstract}

Keywords: Co-creation of value, Relationship marketing, Relationship banking, Relationship management, Banking \& finance, Financial services, Commercial banking, Business banking, Relationship longevity, Governance.

\section{Introduction}

The concept of Co-Creation of Value $(\mathrm{CCoV})$ within the buyer-seller dyad appears to be underresearched in the relationship marketing literature and is in need of further study and clarification, particularly within a banking context. Very little is known about how the consumer engages in CCoV (Payne, Storbacka \& Frow 2008). Therefore, this research will address this concept within a businessbanking context in order to add to the limited literature concerning $\mathrm{CCoV}$. Furthermore, it is essential that managers and board members recognise this aspect of relationship management in conjunction with a robust customer centric corporate governance strategy otherwise customer retention will prove difficult (Obioha \& Garg 2014).

\section{Literature Review}

The traditional value creation process entailed the production of a product/service by the seller and the subsequent consumption by the consumer. Here the roles of the seller and buyer were clearly defined. However today, with the advent of technologies such as the Internet, the consumer demands more

Copyright (C) 2015 Victoria University. This document has been published as part of the Journal of Law and Governance in both online and print formats. Educational and non-profit institutions are granted a non-exclusive licence to utilise this document in whole or in part for personal or classroom use without fee, provided that correct attribution and citation are made and this copyright statement is reproduced. Any other usage is prohibited without the express permission of the publisher. input into the production of products/services as they now have the means to gather information and conduct research. These clearly defined roles became somewhat blurred. By interfering in the production/formulation of products and services, consumers are actually engaging in the process of defining value and creating value along with the seller. Thus CCoV occurs (Prahalad \& 
Ramaswamy 2000, 2004). Prahalad and Ramaswamy (2004) clearly stipulate what CCoV is not. "It is neither the transfer nor outsourcing of activities to customers nor a marginal customization of products and service. Nor is it a scripting or staging of customer events around the firm's various offerings" (p. 6). They go on to say that the aforementioned customer-seller interactions are no longer satisfactory to today's consumer and that the $\mathrm{CCoV}$ involves customer specific personalised interactions. They also emphasise that it is the co-creation experience and not the offering which is the basis of unique value for each customer.

The difference between customisation and personalisation is highlighted by (Prahalad \& Ramaswamy 2000) where customisation "assumes that the manufacturer will design a prouct to suit a customer's needs" (p. 83) whereas personalisation "is about the customer becoming a cocreator of the content of their experiences" (p. 84). It is here where value is created, that is, via experinces (Payne et al. 2008).

There are two focal frameworks for CCoV presented first by Prahalad and Ramaswamy (2004) and then by Payne et al. (2008). Prahalad and Ramaswamy (2004) formulated what they call the DART model which consists of the following building blocks of co-creation:

1. Dialogue - interactivity, engagement, and a propensity to act - on both sides of the customerseller dyad;

2. Access - to information and tools;

3. Risk assessment - probability of harm to the consumer. Should consumers bear some of the risk considering that they are co-creators?

4. Transparency - sellers must aim to have a heightened level of transparency in terms of pricing and product/service information. The nature of the market these days is such that most of this information is available in some form or another and trying to mask it will only contribute to disengaging consumers.

Prahalad and Ramaswamy (2004) suggest that by coupling the above building blocks of co-creation in various ways, that this will develop new and important capabilities such as:

- Access and transparency - enhancement of consumer ability to make informed choices;

- Dialogue and risk assessment - enhancement of ability to engage in debate and co-develop public and private policy choices;

- Access and dialogue - enhancement of the ability to develop and maintain thematic communities; and

- Transparency and risk assessment - enhancement of the ability to co-develop trust.

Payne et al. (2008) present a three part process-based framework which is based on the notion that the buyer-seller dyad is a long term, dynamic and interactive set of experiences and consists of the following three components:

1. Customer value-creating processes - the processes which the customer engages in, in order to manage its business and its relationship with its supplier;

2. Supplier value-creating processes - the processes which the supplier engages in, in order to manage its business and its relationship with its customer;

3. Encounter processes - "the processes and practices of interaction and exchange that take place within customer and supplier relationships and which need to be managed in order to develop successful co-creation opportunities" (pp. 85-6).

\section{Context}

In the 1990s, banks established business-banking units to specifically look after their business clients as historically, business clients were serviced by local branches which had high management turnover (as governed by the policy of the time) therefore impeding the ability of the banks to maintain relationships with their business clients. This new phenomenon was called relationship banking whereby bankers became more customer focused (Nielsen, Terry \& Trayler 1998). In fact, scholars called for a new orientation from a bank focus to a customer focus as early as the 1980s as customers were beginning to lose faith in banks' abilities "to serve them in the manner and with the products they want" (Day \& Wills 1985, p. 5). 
Furthermore, due to the generic and easily replicated nature of banking products, the saturation of branches in local markets, and the same money markets being accessed by the Big 4 banks i.e. National Australia Bank (NAB), Commonwealth Bank of Australia (CBA), Westpac Banking Corporation (WBC) and Australia and New Zealand Banking Group (ANZ) dictating rather generic prices, the 4Ps in the marketing mix (place, product, promotion and prices) were no longer proving an effective marketing strategy within the banking industry.

The point of difference became customer service, defined as "the long-term person-to-person relationship between a financial institution, its distributors and its customer" (Wong \& Perry 1991, p. 12). Moreover, "...poor customer service is like a cancer within an organisation. Good customer service cures this cancer. Furthermore, good customer service fosters growth because each satisfied customer will tell at least five other people about the business, some of whom will become customers" (Wong \& Perry 1991, p. 11).

The subject bank traces its history back over 175 years. It is one of the Big 4 Australian banks and employs over 40,000 people in Australia and overseas. Its business-banking department provides a full range of traditional banking services including risk management, to metropolitan based small to medium sized business clients with a turnover from AUD 5-45 million.

The business-banking service model structure currently offered by the Bank (that was the focus of this research) is one which offers small to medium enterprise (SME) customers as well as small corporate customers direct access to a relationship manager and an assistant manager which form the relationship team. This relationship team owns a portfolio of (on average) 50 customer lending groups which they service and provide all the customers' business-banking needs (in conjunction with product specialists), from lending solutions, typically within the ranges of AUD 1-15 million, transactional banking solutions, foreign exchange, trade finance, interest rate risk management and asset finance to name a few.

It is this relationship, between the relationship manager and the customer that formed the focus of this research as this market segment is an integral part of the Bank's offering (as it is for the rest of the Big 4 banks for that matter) and getting it right is essential for the growth and subsequent maintenance of market share and the ultimate success of the banks as commercial lenders. For this reason, the enhancement of the frontline, (the collective term often used to refer to all the relationship teams across business-banking which are located in different districts/regions across Australia), and its processes are typically under constant review by the leadership team. It is for this reason that this research attempts to provide further understanding of the under-researched construct -Co-Creation of Value - so as to provide the maximum input and output of value within customer/banker relationships and subsequently improve the depth of those said relationships.

\section{Conceptual Framework}

With Prahalad's and Ramaswamy's (2004) considerations in mind, co-reation of value involves customer specific personalised interactions. It is the co-creation experience and not the offering which is the basis of unique value for each customer.

Therefore, within the context of this research, and as illustrated via Figure 1, Co-Creation of Value is where both the customer and the banker, in their dealings together, create what they perceive to be value thereby satisfying their individual and collective needs.

- For the customer, this means that they are able to leverage off the knowledge/experience and network of the relationship manager to the customer's benefit; and

- For the banker, this means that they may have been granted access to the customer's full banking requirement as opposed to sharing part of the banking requirement with a competitor, and commitment to the relationship. 


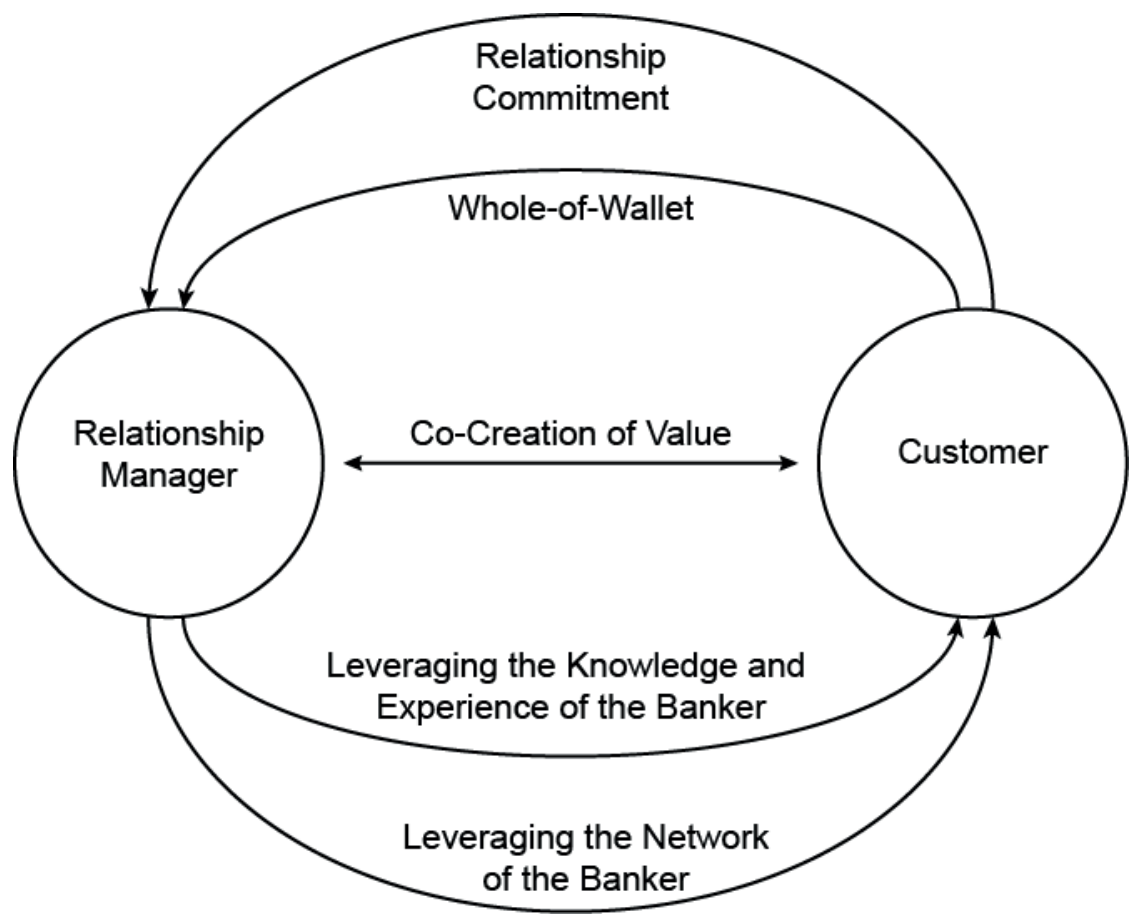

Figure 1: Co-Creation of Value: Exchange Factors

\section{Methodology}

There were two quantitative questionnaires, one targeting the Bank's business-banking relationship managers and the other targeting the Bank's business-banking customers. The questionnaires were targeted at the total population of the respondent groups (for whom correct contact details were available, i.e. valid email addresses) that is, 319 relationship managers and 5,662 business-banking customers (note that the survey was sent to 7,952 business-banking customers, however 2,290 emails were not received due to invalid email address information equating to a $29 \%$ error rate).

\section{Results}

Out of the 319 relationship managers invited to complete the survey, 149 complete responses were captured resulting in a 47 per cent response rate. From the 5,662 customers invited to complete the survey, 68 complete responses were captured resulting in a one per cent response rate.

The following business-banking specific definition for $\mathrm{CCoV}$ (as arrived at by the researcher and discussed in the Conceptual Framework section of this paper) was put to the customer sample:

You and your relationship manager create value together when you are able to leverage off the knowledge/experience and network of your relationship manager to your benefit while the relationship manager enjoys full access to your banking requirements and your commitment to the relationship

Sixty two per cent of the customer sample agreed with this definition thereby suggesting that this definition is an appropriate one within a business-banking context. Further, the CCoV construct was found to be highly correlated with a long-term value adding relationship $(\mathrm{r}=0.947)$.

Similarly, the relationship manager sample were presented with a similar business-banking specific definition for co-creation of value (as arrived at by the researcher and discussed in the Conceptual Framework section of this paper): 
You and your customer create value together when you enjoy full access to your customer's banking requirements and their commitment to the relationship, and they are able to leverage off your knowledge/experience and network

Ninety-six per cent of the relationship manager sample agreed with the above definition. This suggests validation of the above definitions for $\mathrm{CCoV}$ within a business-banking context. Furthermore, the $\mathrm{CCoV}$ construct was found to be highly correlated with a long-term value adding relationship $(\mathrm{r}=0.768)$.

\section{Discussion \& Implications}

It is acknowledged that further research is required in order to better understand this under-researched concept within not only a banking context but in general.

Notwithstanding, we can see from the results in the previous section, that both the customer and relationship manager samples seemingly agree on the same idea of what is $\mathrm{CCOV}$, in that we observe that customers perceive value in being able to leverage off the knowledge/experience and network of their relationship manager. The reciprocal creation of value is then observed, in customers' agreements to assist their relationship manager in attaining value from the relationship by affording the relationship manager full access to the customer's banking requirements, and the customers' commitment to the relationship, thereby co-creating value.

Equally, relationship managers perceive value in enjoying full access to their customers' banking requirements and the customers' commitment to the relationship whilst providing reciprocity in the creation of value by assisting their customers in attaining value from the relationship by enabling their customers to leverage off the relationship manager's knowledge/experience and network.

The above serves to reinforce Prahalad's and Ramaswamy's (2004) considerations in that, it is the cocreation experience and not the offering which is the basis of unique value for each customer. This suggests that banks need to provide value to their customer not only via the token fee waiver or rate reduction, but also via experience based value interactions such as, networking functions, information sessions or personalised introductions to other customers within the bank or portfolio that may have complemetary businesses. However, this not only extends to banks but also to their customers in that, customers should seek to add value to their banker by also affording them reciprocity in this regard and also allowing them access to their network and commitment to the relationship as CCoV appears to be a two-way street.

\section{Conclusion and Recommendations for Future Research}

There is little existing research that covers $\mathrm{CCoV}$, particularly in a banking context, so this study set out to define $\mathrm{CCoV}$ within the said context.

Thus it was proposed by this research that within a banking context, $\mathrm{CCoV}$ occurs where the customer and their relationship manager create value together when the customer is able to leverage off the knowledge/experience and network of the relationship manager to the customer's benefit while the relationship manager enjoys full access to the customer's banking requirements and the customer's commitment to the relationship.

Further to this, the relationship manager may also find value in the customer's network and as such access to the same should be reciprocal.

This study has contributed to the extant literature on value, what it is and how it is co-created within the relational dyad. This contribution is important as the existing theory is quite scarce in this area (Payne et al. 2008). The study has confirmed that the CCoV between a business-banking relationship 
manager and their customer is positively correlated with relationship longevity both from the relationship manager's and customer's perspectives.

A limitation of this study is that due to the lack of extant literature on $\mathrm{CCoV}$, only one measure for this construct was utilised for each respondent group. Therefore factor or reliability analysis was not appropriate. Further research needs to be conducted on this concept as a primary focus in order to better understand it, as it is a factor that promotes relationship 'stickiness' and reciprocity. Another limitation is the low customer response rate (1.2\%). Future studies may wish to provide incentives for customer responses in order to increase the response rate which will in turn provide for a more robust customer sample.

It is recommended that future researchers look to the development of further research measures relevant to this concept. It is also recommended that future research utilises a mix of quantitative as well as qualitative data collection methods as quantitative data is limited in the sense that once it is received, clarification of the responses are not generally provided. However, if the quantitative survey questionnaire can be followed up with a qualitative interview in order to clarify any interesting points, this will provide for a more robust data set and subsequent analysis. Customer focus groups are another mechanism by which future research can attain maximum clarification of survey responses and may also result in a higher response rate.

From a practical business perspective, senior management and/or board members may wish to utilise the definitions proposed within this study (tailoring them to their specific organisational needs). This would assist in ensuring that the organisation's corporate governance policy does not neglect the relational aspect of business, thereby establishing a strong customer-centric policy, and eventually positively influencing the organisation's culture as a result.

\section{References}

Day, A \& Wills, G 1985, 'Critical issues in bank marketing today: an overview', International Journal of Bank Marketing, vol. 3, no. 4, pp. 3-8.

Deeter-Schmelz, DR \& Sojka, JZ 2003, 'Developing effective salespeople: exploring the link between emotional intelligence and sales performance', The International Journal of Organizational Analysis, vol. 11, no. 3, pp. 211-20.

Nielsen, JF, Terry, C \& Trayler, RM 1998, 'Business banking in Australia: a comparison of expectations', International Journal of Bank Marketing, vol. 16, no. 6, pp. 253-63.

Obioha, OO \& Garg, AK 2014, 'Corporate governance practices and customer retention nexus in Nigeria retail banking sector', in NJ Delener, L Fuxman, FV Lu \& S Rodrigues (eds), Managing in an interconnected world: pioneering business and technology excellence, Global Business and Technology Association, New York, pp. 422-9.

Payne, AF, Storbacka, K \& Frow, PE 2008, 'Managing the co-creation of value', Journal of the Academy of Marketing Science, vol. 36, no. 1, pp. 83-96.

Prahalad, CK \& Ramaswamy, V 2000, 'Co-opting customer competence', Harvard Business Review, vol. 78 , no. 1 , pp. $79-87$.

— 2004, 'Co-creating unique value with customers', Strategy \& Leadership, vol. 32, no. 3, pp. 4-9.

Wong, A \& Sohal, A 2002, 'An examination of the relationship between trust, commitment and relationship quality', International Journal of Retail \& Distribution Management, vol. 30, no. 1, pp. 34-50.

Wong, SM \& Perry, C 1991, 'Customer service strategies in financial retailing', International Journal of Bank Marketing, vol. 9, no. 3, pp. 11-6.

Zineldin, M 1995, 'Bank-company interactions and relationships', International Journal of Bank Marketing, vol. 13, no. 2, pp. 30-40. 